\title{
Satisfaction of Physicians Working in a Referral Hospital in Tehran, Iran in 2019
}

\author{
Mohsen Saberi Isfeedvajani ${ }^{1}$, Esmat Davoudi-Monfared ${ }^{2 *}$, Mojtaba Naderi ${ }^{3}$ \\ 'Medicine, Quran and Hadith Research Center \& Department of Community Medicine, Faculty of Medicine, \\ Baqiyatallah University of Medical Sciences, Tehran, Iran \\ ${ }^{2}$ Health Management Research Center \& Department of Community Medicine, Faculty of Medicine, Baqiyatallah \\ University of Medical Sciences, Tehran, Iran \\ ${ }^{3}$ Faculty of Medicine, Baqiyatallah University of Medical Sciences, Tehran, Iran
}

*Corresponding Author: Esmat Davoudi-Monfared, MD, Assistant Professor, Health Management Research Center \& Department of Community Medicine, Faculty of Medicine, Baqiyatallah University of Medical Sciences, Tehran, Iran. Tel: +98-021-81263850, Email: davoudimonfared@gmail.com

Received January 10, 2020; Accepted May 24, 2020; Online Published June 11, 2020

\begin{abstract}
Background: Physicians' satisfaction is closely related to the effectiveness of health services, including quality of services as well as patient compliance, satisfaction, and outcomes.

Objectives: This study was designed to examine the job satisfaction level of physicians working at a referral hospital in Tehran. Methods: This research was a descriptive study performed on a population of physicians working at a referral hospital from April to August 2019. The sample size was calculated as 120 subjects. The Physicians' Job Satisfaction Questionnaire (PJSQ), which is a valid questionnaire, was used as the data collection tool. The collected data was entered into SPSS Statistics 20. Mann-Whitney and $\mathrm{t}$ tests were used for data analysis.

Results: The frequency of female and male physicians was $50(38.2 \%)$ and $81(61.8 \%)$, respectively. The total mean of Job satisfaction in physicians was $51 \pm 7.05$. Overall satisfaction scores were $70.7 \pm 15.1,51.5 \pm 11.1,49.8 \pm 13.1,49.5 \pm 11.2,44.1 \pm 9.3$, and $40.5 \pm 11.9$ in domains of income satisfaction, physicians' satisfaction with management, relationship between physicians and their colleagues, patients, staff, and physicians' job satisfaction, respectively. $87 \%$ of physicians participating in this study were not willing to leave their jobs. The income satisfaction of the female physician group was significantly higher than that of men $(P=0.029)$. The income satisfaction of subspecialists was significantly higher than that of specialists $(P=0.022)$. The job satisfaction of physicians who were not faculty members was significantly higher than that of physicians who were faculty members $(P=0.034)$. Conclusion: The job satisfaction level of physicians working at a referral hospital in Tehran was moderate. Income satisfaction and job satisfaction were the highest and lowest levels of satisfaction, respectively.

Keywords: Satisfaction, Job, Physicians, Iran
\end{abstract}

\section{Background}

Job satisfaction is considered to be a set of compatible or incompatible feelings that employees hold toward their jobs. In fact, it is an emotional state resulting from job evaluation, the emotional reaction to the job, and an individual's attitude toward his/her job. ${ }^{1}$

Previous studies have categorized factors that determine job satisfaction into three groups: personal characteristics, comprising age, gender, education level, race, and marital status; occupational characteristics comprising absolute and relative income, working hours, number of responsibilities, and attitude toward the job; and workplace characteristics, comprising number of employees, expertise, control over workplace, and support from colleagues. ${ }^{2,3}$

New policies that have been enforced in recent years have resulted in increases to physicians' workload, stress, and responsibilities on the one hand, and decreases in their autonomy and income in some disciplines, even major ones $^{4}$. Physicians' satisfaction in all places and specialties is no longer acceptable. Physicians' job satisfaction levels in a wide range of occupational dimensions have been reported to be between $27 \%$ and $96 \% .^{5-7}$

A study in the United States showed that physicians' job satisfaction declined between 1997 and 2001. This study reported that $42.4 \%$ of family physicians and $43.3 \%$ of specialists had a very high level of job satisfaction in 1997, while about $38.5 \%$ of family physicians and $41.4 \%$ of specialists showed a very high level of job satisfaction in $2001 .^{8}$ Job satisfaction is a multidimensional concept suggesting that people may be satisfied with some aspects of a job and at the same time dissatisfied with others. Some dimensions of job satisfaction are more important

Copyright $\odot 2020$ The Author(s). This is an open-access article distributed under the terms of the Creative Commons Attribution License (http:// creativecommons.org/licenses/by/4.0), which permits unrestricted use, distribution, and reproduction in any medium, provided the original work is properly cited. 
and can affect overall job satisfaction among specialists to a greater degree. Such dimensions are income, weekly working hours, gender, number of on-call hours, lifestyle, and difficulty of job. ${ }^{9}$

Physicians' satisfaction is closely related to the effectiveness of their services, including the quality of care they provide, patient's compliance to recommended care and treatment, patient satisfaction with received services, and patient's health outcomes. ${ }^{10}$ Job satisfaction not only increases the work efficacy of physicians, but also affects their own physical and mental health. ${ }^{11,12}$ Thus, physicians' satisfaction level is important, as it can affect their health as well as the health of patients and decisions of managers and policymakers.

\section{Objectives}

This study was designed to examine the level of satisfaction of physicians working at a referral hospital in Tehran due to the importance of this issue and the fact that job satisfaction among physicians working at the hospital has not been studied from different dimensions yet.

\section{Methods}

This research is a descriptive cross-sectional study. The study population consisted of all physicians working at a referral hospital in Tehran, Iran from April to August 2019. Stratified random sampling was conducted on different groups of physicians, and all general practitioners, specialists, and subspecialists, permanent and contractual physicians, physicians who are faculty members, and who are not faculty members, full-time and part-time physicians working at the hospital in Tehran were asked to respond to questions. Inclusion criteria included being 30 to 50 years of age and consenting to participate in the study. Responding to less than $50 \%$ of the questions was the exclusion criterion.

The sample size was calculated to be 169 people using Morgan's formula, and it was corrected to 108 people using the limited population formula; 120 people were included by considering a population loss of $10 \%$. The necessary coordination was made with the Vice President for Research and Technology of the hospital to collect data after the research plan was approved by the University Research Council and a code of ethics was obtained. Using the simple random sampling method, a sample of physicians with moderate financial performance who worked at least two days per week at the hospital was selected. The Standard Physicians' Job Satisfaction Questionnaire (PJSQ), whose validity and reliability was previously proven in a study by Alaghehmand et al, was used as a data collection tool. ${ }^{13}$ The explanatory factor analysis of PJSQ showed 4 factors with $53.6 \%$ total variance and 0.85 Kaiser-MeyerOlkin Index. The reliability was determined to be 0.83 using the Cronbach's Alpha method. The PJSQ includes 6 components (relationship with patient, relationship with colleagues, relationship with staff, income satisfaction, satisfaction with management, satisfaction with working as a physician) and 33 sub-components and is based on a 5-point Likert scale. Questionnaires were distributed and collected (after completion) by a trained researcher who visited the study subjects in person and asked for their approval to collect data. Physicians who did not intend to cooperate were excluded from the study.

Data from the questionnaires was entered into SPSS Statistics 20 software. The percentages of frequency of distribution, mean and standard deviation were used consecutively to perform descriptive statistical tests for qualitative and quantitative variables. Moreover, MannWhitney and $t$ test were used as inferential statistical tests. The significance level was set at $5 \%$ in this study.

\section{Results}

A total of 131 physicians were studied. The frequency percentage of male physicians was higher than female physicians (61.8\%). The descriptive characteristics of patients are shown in Table 1. The highest overall satisfaction score among dimensions of overall job satisfaction equaled $70.7 \pm 15.12$ and belonged to the overall income satisfaction dimension. The lowest overall satisfaction score among dimensions of overall job satisfaction equaled $40.5 \pm 11.99$ and belonged to the dimension of overall satisfaction with working as a physician. The overall job satisfaction score was determined to be $51 \pm 7.05$ in the domain of physician's satisfaction with management (Table 2).

Most of the physicians that took part in this study were reluctant to leave their jobs (87\%). The average scores of overall satisfaction for male and female physicians were not significantly different in any dimension except income satisfaction; the income satisfaction of female physicians was significantly higher than that of male physicians $(P=0.029)$. Furthermore, the average score for the income satisfaction dimension of subspecialists was significantly higher than that of specialists $(P=0.022)$. Average satisfaction score in the dimensions of relationship with patients, relationship with colleagues, relationship with staff, management, satisfaction with working as a physician, and overall satisfaction of both groups had no statistically

Table 1. Descriptive Characteristics of Physicians Participating in the Job Satisfaction Study

\begin{tabular}{llcc}
\hline & & Percent & No. \\
\hline \multirow{3}{*}{ Gender } & 50 & 38.2 & Female \\
& 81 & 61.8 & Male \\
& 131 & 100 & Total \\
Education level & 5 & 3.8 & General practitioner \\
& 82 & 62.6 & Specialist \\
Faculty member & 44 & 33.6 & Subspecialist \\
& 103 & 100 & Total \\
Full-time physician & 54 & 58.8 & Yes \\
& 131 & 41.2 & No \\
& 60 & 100 & Total \\
& 122 & 49.3 & Yes \\
& & 51.7 & No \\
& 100 & & Total \\
\hline
\end{tabular}


Table 2. Comparison of Mean and Standard Deviation of Medical Job Satisfaction Components in the Studied Physicians

\begin{tabular}{|c|c|c|c|}
\hline & Component & Mean & S.D \\
\hline \multirow{6}{*}{$\begin{array}{l}\text { Relationship } \\
\text { with the patient }\end{array}$} & The feeling of a good relationship with the patient & 28.5 & 10.2 \\
\hline & Patient's reasonable and fundamental requests & 58.0 & 18.5 \\
\hline & Not considering time constraints as a barrier to having a proper relationship with the patient & 55.0 & 22.0 \\
\hline & Ability to provide optimum healthcare most of the time & 60.8 & 20.8 \\
\hline & Allocating enough time to provide the care that patients need & 45.6 & 17.7 \\
\hline & Overall satisfaction with the domain of relationship with the patient & 49.5 & 11.2 \\
\hline \multirow{5}{*}{$\begin{array}{l}\text { Relationship } \\
\text { with colleagues }\end{array}$} & Getting positive incentive from other physician colleagues & 59.7 & 19.6 \\
\hline & Spending good times with physician colleagues & 45.3 & 17.4 \\
\hline & No work conflict with physician colleagues & 47.3 & 16.4 \\
\hline & Timely support from my colleagues & 47.0 & 17.5 \\
\hline & Overall satisfaction with the domain of relationship with colleagues & 49.8 & 13.1 \\
\hline \multirow{5}{*}{$\begin{array}{l}\text { Relationship } \\
\text { with staff }\end{array}$} & Staff acceptance of my diagnosis during the therapeutic procedure & 37.1 & 9.9 \\
\hline & Proper cooperation of other employees when providing medical services & 41.7 & 13.4 \\
\hline & Reliable compliance of other staff members with clinical standards during the therapeutic procedure & 51.8 & 17.7 \\
\hline & Proper support from other staff members when providing medical services & 45.8 & 13.7 \\
\hline & Overall satisfaction with the domain of relationship with staff & 44.1 & 9.3 \\
\hline \multirow{5}{*}{$\begin{array}{l}\text { Income } \\
\text { satisfaction }\end{array}$} & Fairness of a total reward paid to me & 66.8 & 20.7 \\
\hline & Suitability of proper criteria for merit pay & 72.7 & 20.1 \\
\hline & Proportionality of paid reward with my expertise and experience & 71.4 & 17.1 \\
\hline & Suitability of paid reward compared to other medical specialties & 72.0 & 18.0 \\
\hline & Overall income satisfaction & 70.7 & 15.1 \\
\hline \multirow{6}{*}{$\begin{array}{l}\text { Satisfaction with } \\
\text { management }\end{array}$} & Availability of medical facilities and equipment when needed & 48.6 & 18.9 \\
\hline & Suitability of my room space for visiting the patient & 45.0 & 19.9 \\
\hline & How logical and scientific are decisions of chief physician & 58.4 & 17.8 \\
\hline & Good job performance of senior hospital managers & 57.7 & 17.6 \\
\hline & Good managing skill of chief physician of each department (ward) & 49 & 19.03 \\
\hline & Overall physician's satisfaction with management & 51.5 & 11.1 \\
\hline \multirow{7}{*}{$\begin{array}{l}\text { Satisfaction with } \\
\text { working as a } \\
\text { physician }\end{array}$} & Sense of belonging to the workplace and considering myself as a member of this workplace & 34.7 & 15.3 \\
\hline & Overall satisfaction with my job & 36.8 & 12.8 \\
\hline & My promising occupational status & 43.7 & 18.9 \\
\hline & Conformity of working as a physician with my expectations and desires & 51.5 & 20.8 \\
\hline & Choosing to be a physician again if there were other options & 35.2 & 18.5 \\
\hline & Overall satisfaction with working as a physician & 40.5 & 11.9 \\
\hline & Overall job satisfaction & 51 & 7.05 \\
\hline
\end{tabular}

significant difference $(P>0.05)$.

The average score of the dimension of medical job satisfaction of physicians who were not faculty members was significantly higher than that of physicians who were faculty members $(P=0.034)$. The average scores of satisfaction in the dimensions of relationship with the patient, relationship with colleagues, relationship with staff, income level, management, medical job satisfaction, and overall satisfaction were not significantly statistically different in either group studied $(P>0.05)$.

\section{Discussion}

The present study found that the overall satisfaction level of physicians working in a referral hospital in Tehran was moderate. Physicians' overall job satisfaction was the lowest level of satisfaction, and physicians' satisfaction in the relationship domain (relationships with staff, patients, and colleagues) was measured as below average. The income satisfaction level was the highest level of satisfaction, and the physicians' satisfaction with management domain was above average. Women show greater overall job satisfaction compared to men, and income satisfaction was significantly higher in the female physicians group than in the group of male physicians. Subspecialists had more overall job satisfaction than specialists.

It is necessary to understand the factors that lead to satisfaction or dissatisfaction, because dissatisfaction can have adverse effects on the quality of care, cost, and outcome of healthcare as well as physicians' health. ${ }^{14}$

Overall job satisfaction among the physicians in the 
current study was moderate. This finding is similar to findings of other studies. Abdol-Rahman et al conducted a study in Egypt and reported that the satisfaction level of physicians was measured to be below average. ${ }^{15}$ Alsaqabi et al conducted a research in Kuwait and reported that job satisfaction among physicians was 50\%. ${ }^{16}$ Generally, an inadequate number of clinical centers, a high number of patients, and high work pressure have been reported to be the most important factors of physicians' dissatisfaction.

Higher job satisfaction among physicians is found in developed countries, which is inconsistent with the current results and the results of studies mentioned above. Brøndt et al completed an investigation in Denmark and reported high job satisfaction among physicians. ${ }^{17}$ Nylenna et al reported a high level of physicians' satisfaction; $52.9 \%$ of physicians showed a very high overall satisfaction. ${ }^{18}$ Low working hours, older age, and high income were mentioned as the most important factors of high job satisfaction in these studies.

The present study found that female physicians showed higher job satisfaction than male physicians, especially in the domain of income. A study done by Ozyurt et al suggested that no significant difference was observed between men and women in Turkey in terms of job satisfaction. ${ }^{19}$ Furthermore, there was no relationship between gender and job satisfaction in a systematic review study on job satisfaction in the United States. ${ }^{20}$ Female physicians reported higher income satisfaction than male physicians in an investigation conducted by Goetz et al in Germany. ${ }^{21}$

"Sense of belonging to the workplace and considering myself as a member of this work" is the component of medical job satisfaction with the lowest average score. Organizational sense of belonging is one of the important factors of an individual's loyalty to an organization. Research has shown that having a sense of organizational belonging is directly related to optimum job performance, while it has a reverse effect on the tendency to leave work and dissatisfaction. ${ }^{22}$ Because having a sense of organizational belonging is of great importance, its low level in physicians can significantly affect the quality of their work in the hospital.

The current study found the lowest level of satisfaction to be in the domain of relationship with the patient. Overall job satisfaction of physicians has a direct impact on the patient-physician relationship. Haas et al reported that physicians who had higher professional satisfaction had more satisfied patients. Further research is needed to determine the factors that may mediate the relationship between patients' and physicians' satisfaction. ${ }^{23}$

The current study also found that physicians who were faculty members were less dissatisfied compared to physicians who were not faculty members. The numerous responsibilities of physicians who are faculty members and the heavier workload they are expected to accomplish can be considered as reasons for lower job satisfaction among
Research Highlights

What Is Already Known?

New policies that have been enforced in recent years have increased physicians' workloads, stress, and responsibilities. Physicians' satisfaction is closely related to the effectiveness of health services, including the quality of healthcare, patient's compliance with treatment, patient satisfaction, and patient's health outcomes.

\section{What This Study Adds?}

The job satisfaction level of physicians working at a referral hospital in Tehran was moderate, and this may affect their job activities. Income satisfaction medical job satisfaction were the highest and lowest levels of satisfaction, respectively. Such low levels of satisfaction can have significant effects on health outcomes.

these physicians compared to physicians who are not faculty members.

The consequences of physicians' dissatisfaction have been little studied, but they can be explained based on previous experiences. Studies have shown that the most important effect of physicians' job satisfaction is on the quality of medical services. ${ }^{24}$ Physicians' dissatisfaction leads to poor job performance, reduced commitment to perform assigned tasks, increased risk of prescribing high-risk medications, and increased likelihood of quitting follow-up treatment. ${ }^{25}$ The next consequence of dissatisfaction is job quitting. ${ }^{26}$ It was reported by Landon et al that dissatisfied physicians were 2 to 3 times more likely to quit their job compared to satisfied physicians. ${ }^{27}$

\section{Conclusion}

The job satisfaction level of physicians working at a referral hospital in Tehran was moderate. Income satisfaction and medical job satisfaction were the highest and lowest levels of satisfaction, respectively. Medical job satisfaction was higher among physicians who were not faculty members than physicians who were faculty members. It is suggested that the effect of physicians' job satisfaction on the quality of services provided in the hospital be carefully examined in future studies and strategies be identified to reduce its negative consequences on the quality of medical services.

\section{Authors' Contributions}

MSI: The study topic and design suggestion. ED: manuscript writing and critical revisions. $\mathrm{MN}$ : data collection, analysis, and interpretation.

\section{Conflict of Interest Disclosures}

The authors declare that they have no conflicts of interest.

\section{Ethical Approval}

This study was approved by the Institutional Review Board and local Ethics Committee of Baqiyatallah University of 
Medical Sciences. The ethical approval code of this study is IR.BMSU.REC.1398.102.

\section{Acknowledgments}

The researchers wish to express their appreciation for the guidance and advice given by the Clinical Research Development Unit of Baqiyatallah Hospital.

\section{References}

1. Ng TW, Sorensen KL, Yim FH. Does the job satisfaction-job performance relationship vary across cultures? J Cross Cult Psychol. 2009;40(5):761-796. doi:10.1177/0022022109339208.

2. Kabbash IA, El-Sallamy RM, Abdo SAE, Atalla AO. Job satisfaction among physicians in secondary and tertiary medical care levels. Environ Sci Pollut Res Int. 2020. doi:10.1007/ s11356-020-08506-9.

3. Gazioglu S, Tansel A. Job satisfaction in Britain: individual and job related factors. Appl Econ. 2006;38(10):1163-1171. doi:10.1080/00036840500392987.

4. Linzer M, Konrad TR, Douglas J, et al. Managed care, time pressure, and physician job satisfaction: results from the physician worklife study. J Gen Intern Med. 2000;15(7):441450. doi:10.1046/j.1525-1497.2000.05239.x.

5. Katz A, Mallory B, Gilbert JC, et al. State of the practice for pediatric surgery--career satisfaction and concerns. A report from the American Pediatric Surgical Association Task Force on Family Issues. J Pediatr Surg. 2010;45(10):1975-1982. doi:10.1016/j.jpedsurg.2010.05.011

6. Bernabeu-Wittel M, García-Morillo S, Pérez-Lázaro IJ, et al. Work, career satisfaction, and the position of general internists in the south of Spain. Eur J Intern Med. 2005;16(6):454-460. doi:10.1016/j.ejim.2005.02.019.

7. Rosta J, Aasland OG, Nylenna M. Changes in job satisfaction among doctors in Norway from 2010 to 2017: a study based on repeated surveys. BMJ Open. 2019;9(9):e027891. doi:10.1136/ bmjopen-2018-027891.

8. Al Juhani AM, Kishk NA. Job satisfaction among primary health care physicians and nurses in Al-madinah Al-munawwara. J Egypt Public Health Assoc. 2006;81(3-4):165-180.

9. Misra-Hebert AD, Kay R, Stoller JK. A review of physician turnover: rates, causes, and consequences. Am J Med Qual. 2004;19(2):56-66. doi:10.1177/106286060401900203.

10. Halbesleben JR, Rathert C. Linking physician burnout and patient outcomes: exploring the dyadic relationship between physicians and patients. Health Care Manage Rev. 2008;33(1):29-39. doi:10.1097/01.hmr.0000304493.87898.72.

11. Weng HC, Hung CM, Liu YT, et al. Associations between emotional intelligence and doctor burnout, job satisfaction and patient satisfaction. Med Educ. 2011;45(8):835-842. doi:10.1111/j.1365-2923.2011.03985.x.

12. Kansoun Z, Boyer L, Hodgkinson M, Villes V, Lançon C, Fond
G. Burnout in French physicians: a systematic review and metaanalysis. J Affect Disord. 2019;246:132-147. doi:10.1016/j. jad.2018.12.056.

13. Alaghemand $\mathrm{MH}$, Hojatdost $M$, Ghahvehchi-Hosseini $F$, Gholami Fesharaki M. Studying the validity and reliability of the Baqiyatallah Physician's Job Satisfaction Questionnaire. Journal of Military Medicine. 2015;17(2):57-63. [Persian].

14. Faragher EB, Cass M, Cooper CL. The relationship between job satisfaction and health: a meta-analysis. Occup Environ Med. 2005;62(2):105-112. doi:10.1136/oem.2002.006734.

15. Abdel-Rahman AG, Abdel Halim AW, Allam MF, Meky F. Low job satisfaction among physicians in Egypt. TAF Prev Med Bull. 2008;7(2):91-96.

16. Alsaqabi FB, Aldousari A, Ismail AE, El-Shazly M. Job satisfaction among physicians in Al-Sabah hospital, Kuwait. Alex J Med. 2010;46(2):83-90.

17. Brøndt A, Vedsted $\mathrm{P}$, Olesen F. [General practitioners' job satisfaction]. Ugeskr Laeger. 2007;169(26):2521-2525.

18. Nylenna M, Aasland OG. [Job satisfaction among Norwegian doctors]. Tidsskr Nor Laegeforen. 2010;130(10):1028-1031. doi:10.4045/tidsskr.09.0955.

19. Ozyurt A, Hayran O, Sur H. Predictors of burnout and job satisfaction among Turkish physicians. QJM. 2006;99(3):161169. doi:10.1093/qjmed/hcl019.

20. Scheurer D, McKean S, Miller J, Wetterneck T. U.S. physician satisfaction: a systematic review. J Hosp Med. 2009;4(9):560568. doi:10.1002/jhm.496.

21. Goetz K, Musselmann B, Szecsenyi J, Joos S. The influence of workload and health behavior on job satisfaction of general practitioners. Fam Med. 2013;45(2):95-101.

22. Bakker AB, Demerouti E, Verbeke W. Using the job demandsresources model to predict burnout and performance. Hum Resour Manage. 2004;43(1):83-104. doi:10.1002/hrm.20004.

23. Haas JS, Cook EF, Puopolo AL, Burstin HR, Cleary PD, Brennan TA. Is the professional satisfaction of general internists associated with patient satisfaction? J Gen Intern Med. 2000;15(2):122-128. doi:10.1046/j.1525-1497.2000.02219.x.

24. Grembowski D, Ulrich CM, Paschane D, et al. Managed care and primary physician satisfaction. J Am Board Fam Pract. 2003;16(5):383-393. doi:10.3122/jabfm.16.5.383.

25. Williams ES, Skinner AC. Outcomes of physician job satisfaction: a narrative review, implications, and directions for future research. Health Care Manage Rev. 2003;28(2):119-139. doi:10.1097/00004010-200304000-00004.

26. Freeborn DK. Satisfaction, commitment, and psychological wellbeing among HMO physicians. West J Med. 2001;174(1):13-18. doi:10.1136/ewjm.174.1.13

27. Landon BE, Reschovsky JD, Pham HH, Blumenthal D. Leaving medicine: the consequences of physician dissatisfaction. Med care. 2006:44(3):234-42. doi: 10.1097/01. mlr.0000199848.17133.9b 